\title{
Conspicuous work: Peer working time, labour supply, and happiness
}

Citation for published version (APA):

Collewet, M., de Grip, A., \& de Koning, J. (2017). Conspicuous work: Peer working time, labour supply, and happiness. Journal of Behavioral and Experimental Economics, 68, 79-90.

https://doi.org/10.1016/j.socec.2017.04.002

Document status and date:

Published: 01/06/2017

DOI:

10.1016/j.socec.2017.04.002

Document Version:

Publisher's PDF, also known as Version of record

Document license:

Taverne

Please check the document version of this publication:

- A submitted manuscript is the version of the article upon submission and before peer-review. There can be important differences between the submitted version and the official published version of record.

People interested in the research are advised to contact the author for the final version of the publication, or visit the DOI to the publisher's website.

- The final author version and the galley proof are versions of the publication after peer review.

- The final published version features the final layout of the paper including the volume, issue and page numbers.

Link to publication

\footnotetext{
General rights rights.

- You may freely distribute the URL identifying the publication in the public portal. please follow below link for the End User Agreement:

www.umlib.nl/taverne-license

Take down policy

If you believe that this document breaches copyright please contact us at:

repository@maastrichtuniversity.nl

providing details and we will investigate your claim.
}

Copyright and moral rights for the publications made accessible in the public portal are retained by the authors and/or other copyright owners and it is a condition of accessing publications that users recognise and abide by the legal requirements associated with these

- Users may download and print one copy of any publication from the public portal for the purpose of private study or research.

- You may not further distribute the material or use it for any profit-making activity or commercial gain

If the publication is distributed under the terms of Article $25 \mathrm{fa}$ of the Dutch Copyright Act, indicated by the "Taverne" license above, 


\title{
Conspicuous work: Peer working time, labour supply, and happiness
}

\author{
Marion Collewet ${ }^{\mathrm{a}, *}$, Andries de Grip ${ }^{\mathrm{b}}$, Jaap de Koning ${ }^{\mathrm{c}}$ \\ ${ }^{a}$ Center for Operations Research and Econometrics (CORE), Université Catholique de Louvain, Voie du Roman Pays, 34 - L1.03.01, 1348 Louvain-la-Neuve, \\ Belgium; ROA, Maastricht University \\ ${ }^{\mathrm{b}}$ ROA and Department of Economics, Maastricht University, IZA; Netspar; P.O. Box 616, 6200 MD, Maastricht, Netherlands \\ ' SEOR, Erasmus University Rotterdam, Marconistraat 16, 3029AK Rotterdam, Netherlands
}

\section{A R T I C L E I N F O}

\section{Article history:}

Received 9 November 2016

Revised 7 April 2017

Accepted 7 April 2017

Available online 13 April 2017

\section{Keywords:}

Well-being

Social norms

Working hours

Status

\begin{abstract}
A B S T R A C T
While spillovers among peers in effort and productivity have been studied thoroughly, little is known about peer effects in working time. In this paper, we relate a unique measure of peer weekly working time from a Dutch panel to men's working time and to their happiness, in order to find out how peer working time enters men's utility function. We find that men's working time increases with that of their peers, and that men's happiness is negatively related to peer working time. Our findings are consistent with a 'conspicuous work' model, in which working time is a source of status. The paper therefore provides evidence of a new form of status seeking that can drive peer effects in working time.
\end{abstract}

(c) 2017 Elsevier Inc. All rights reserved.

\section{Introduction}

Individuals' labour supply decisions are likely to be influenced by their peers' behaviour, but it is very difficult to find clean evidence of peer effects in working time. The aim of this paper is to find which motivations could drive following behaviour in working time, by studying the role peer working time plays in an individual's utility function. To do so, we analyse how peer working time relates to both the working time and happiness of Dutch male workers.

Peer behaviour, and peer working time in particular, can enter an individual utility function in various ways. Apart from the relative income motive, for which we control in our analysis, we identify three main models. First, peer working time can generate externalities and therefore influence the marginal utility of leisure or of work for an individual (see the spillover effects of Grodner and Kniesner, 2006). Second, an individual can have a preference for conformity and thus derive utility from working the same number of hours as his peers (see the conformity effects of Grodner and Kniesner, 2006). Third, the individual can derive status and therefore utility from the difference between his own working time and that of his peers (see the emulation model of Clark and Oswald, 1998). If the individual derives status from working less than his peers, this is a case of 'conspicuous leisure' (Veblen, 1899). Alterna-

\footnotetext{
* Corresponding author.

E-mail addresses: marion.collewet@uclouvain.be (M. Collewet), a.degrip@maastrichtuniversity.nl (A. de Grip), dekoning@seor.eur.nl (J. de Koning).
}

tively, in what we call the 'conspicuous work' case, the individual derives status from working more than his peers, which increases his utility.

We use data from the CentER data panel, a panel survey of Dutch households, in which respondents are asked about the weekly working time of their acquaintances. We show that some of the most obvious sources of bias in reports about peers can be ruled out empirically. Our results build on this finding. We first find a positive relation between a man's working time and that of his male peers, as found in earlier studies and as predicted by all three models mentioned above. Second, we find that men are less happy if their male peers work more, even after controlling for their own working time and for their own and peer income. This is consistent with a conspicuous work model in which individuals derive status from their working time and in which the optimal behaviour is to imitate one's peers. We use individual fixed effects to control for unobserved characteristics, including those that individuals might share with their peers, and we are able to rule out a series of other potential sources of bias.

We study the role of peer working time in an individual's utility function by examining the relation between peer working time and individual happiness. This means that we use self-reported happiness as a proxy for utility. This approach has yielded interesting insights in other fields such as the study of the potentially imitative character of obesity (Blanchflower et al., 2009; Oswald and Powdthavee, 2007). We here apply it to the study of working time.

Earlier studies by Aronsson et al. (1999), Weinberg et al. (2004) and Grodner and Kniesner (2008) have attempted to derive causal evidence of peer effects in working time from obser- 
vational data, without having entirely exogenous sources of variation in peer working time. ${ }^{1}$ In this paper, we provide evidence of a mechanism which can drive following behaviour in working time. Finding this mechanism provides further support for the existence of a causal link running from peer to own working time. In addition, we use direct information on peer labour supply, namely, the average weekly working time of a man's acquaintances, as reported by the respondent himself, while earlier studies use the working time of workers with characteristics similar to the individual's (e.g. Aronsson et al., 1999) or a working time variable constructed on the basis of other peer characteristics described by the individual (Woittiez and Kapteyn, 1998).

The policy implications of our findings are twofold. First, following behaviour in working time could call for regulation if it leads to a rat race in which individuals invest in maintaining their relative working time position at the cost of things which matter in absolute terms (such as rest and health). However, we do not find much evidence of such a race for the Netherlands. Second, knowing more about the motivations behind peer effects in working time is important for the design of incentives. The implications for optimal taxation of relative income concerns and of other positional concerns have been studied by e.g. Aronsson and Johansson-Stenman (2013, 2014) and Mujcic and Frijters (2015). If relative working time also plays a role in people's utility functions, this should be taken into account.

The paper is structured as follows. The next section formulates different models for the different ways in which peer labour supply can influence an individual's utility and his labour supply. It also gives a brief overview of the empirical literature. Section 3 describes the data. Section 4 tests the different models formulated earlier, first, by analysing the link between peer working time and men's own working time and, second, by studying how peer working time relates to men's happiness. Section 5 concludes the paper.

\section{Social interactions in labour supply}

\subsection{Models of social interactions in labour supply}

\subsubsection{Externalities}

A first way to explain why individuals are affected by their peers' working time is to argue that peer working time generates externalities. Working alone or relaxing alone is arguably less enjoyable than working or relaxing with others. Kahneman et al. (2004) provide evidence that time spent alone is the time of the day that is enjoyed least. Alesina et al. (2006) present a simple model accounting for what they call a social multiplier effect in leisure and use it to explain differences in hours worked between the United States and Europe. Vendrik (1998) develops a model that explains long-run changes in labour supply by bandwagon effects, that is, by the fact that individual preferences are influenced by average behaviour in their social group. Grodner and Kniesner (2006) model a similar idea under the name spillover effects. Similarly, Stiglitz (2008) argues that the marginal utility of leisure decreases when others work more because it is more enjoyable to spend leisure time together. There is indeed evidence that individuals coordinate their working hours to have common leisure time within the household (Hamermesh, 2002) and within regions (Jenkins and Osberg, 2004; Georges-Kot et al., 2014).

\footnotetext{
1 Spillovers at work among peers in effort and productivity have been well documented using experiments (see the seminal papers by Falk and Ichino (2006) and Mas and Moretti (2009), and all their followers). But experimental evidence is more difficult to obtain for peer effects in working time.
}

The individual's utility function, in such a case, takes the form ${ }^{2}$

$U=U(h, h \bar{h}, c, X)$

where $h$ stands for the weekly working time of the individual, $\bar{h}$ is the weekly working time of the relevant peer group, $c$ is the consumption of market goods and services, and $X$ is a vector of personal characteristics and tastes. Here $U_{h \bar{h}}>0$, meaning that the individual enjoys working more the more his peers work.

In all the models presented in this section, the labour supply function takes the form

$H=H(w, y, \bar{h}, X)$

where $w$ represents the hourly wage rate an individual can command on the labour market and $y$ is his non-labour income. In the externalities model, $H_{\bar{h}}>0$, because an increase in peer hours leads to an increase in the marginal utility from work (and conversely to a decrease in the marginal utility from leisure) for the individual. $^{3}$

\subsubsection{Conformity}

Second, peer working time can set a norm to which individuals want to conform. Akerlof's (1980) theory of social custom and the identity theory of Akerlof and Kranton (2000) state that an individual's utility will be enhanced through an increase in identity utility if he behaves as people from his social category are expected. In the case of working time, this means that an individual will dislike having working hours that deviate greatly from what is expected of people in his social category. His peers' working hours can be considered a reasonable proxy for what is expected. Vendrik (2003) develops a specific version of the theory of social custom for labour supply. Clark (2003) shows that unemployed men are happier if their peers are unemployed as well and interprets this as evidence that unemployment can constitute a social norm. Grodner and Kniesner (2006) call such normative effects of the average labour supply in a group conformity effects. ${ }^{4}$ Analogous to their model, we can model the individual utility function in this case as

$U=U\left((h-\bar{h})^{2}, h, c, X\right)$

where $U_{(h-\bar{h})^{2}}<0$, since there is a reputation cost of deviating from the social norm. This specification ensures that there is no reputation effect if the individual complies to the norm and a negative one if he deviates from it (see Clark, 2003).

In the labour supply function, again, $H_{\bar{h}}>0$, because the longer a man's peers work, the more he is willing to work himself, since he wants to conform to the social norm of working long hours. ${ }^{5}$ Bernheim (1994) develops a model in which individuals who care about status derived from complying with the social norm tend to conform to a homogeneous standard of behaviour, even if their preferences regarding that behaviour differ. Social norms held by individuals or by the people around them have been shown to influence the division of household and market work in couples (Van der Lippe and Siegers, 1994). Stutzer and Lalive (2004) show

\footnotetext{
2 This is a specific form of an interaction model. We choose to test this form because it is common in the literature (Vendrik, 1998; Grodner and Kniesner, 2006).

${ }^{3}$ To allow for this interpretation, we need to abstract from the issue of the timing of work by assuming that everyone works roughly during the same hours.

${ }^{4}$ In a model of labour supply at the household level, Aronsson and Granlund (2015) also incorporate into the utility function similar terms that describe the loss in utility which results from deviating from men's market work norm and women's household work norm.

5 Grodner and Kniesner (2006) show how conformity effects and spillover effects have different implications for peer effects on labour supply: While the former lead to labour supply tending towards the mean of the reference group, the latter lead to a snowball increase in labour supply.
} 
that individuals in communities with a stronger social norm to work tend to have shorter unemployment durations. Burda et al. (2013) find that theories based on social norms are consistent with the distribution of work across genders in a number of countries.

\subsubsection{Status: conspicuous leisure or conspicuous work?}

A third way to explain social interactions in labour supply is to start from the idea that individuals derive status from the difference between their own labour supply and that of others. Clark and Oswald (1998) develop a general model of the behavioural implications of striving for status through differentiation. Applying their model to the case in which status can be derived from labour supply behaviour, one obtains an individual utility function of the form

$U=U(s, h, c, X)$

where $s$ is a status term, which in our case can take the form $s=h-\bar{h}-$ in the case of what Clark and Oswald (1998) call additive comparisons - or $s=h / \bar{h}$ - in the case of ratio comparisons. How exactly this status term affects individual utility depends on whether individuals derive status from having more leisure than their peers or from working more.

Veblen (1899) coined the concept of conspicuous leisure, that is, the idea that individuals can prove their status not only by consuming expensive and exclusive goods (conspicuous consumption), but also by showing that they do not have to work much and can afford to learn all kinds of skills that are not directly productive. Frijters and Leigh (2008) depict individuals in present times as making trade-offs between investing in conspicuous consumption and in conspicuous leisure and show that the balance is shifting towards the first element as mobility increases and leisure activities are less easily registered by one's environment. In the presence of conspicuous leisure, we have $U_{s}<0$ and therefore also $U_{\bar{h}}>0$.

However, individuals nowadays also signal their status to others through working time itself. In many social groups, an individual can indeed increase his status by telling everyone that he is very busy, preferably even more than others around him. Symmetrically, he can lose status if he has less to do than others. We label the case in which working time is viewed as a provider of status conspicuous work. Clark and Oswald (1998, p. 144) cite emulation in labour supply as a possible application of their model: 'One example is the Japanese-style case of corporate cultures in which everyone works at high levels of effort. When performance gives status, either directly or through added earnings, the model predicts effort-following'. Experimental results by Falk and Ichino (2006) also seem in line with the idea of conspicuous work: They find that individuals are more productive in their job if they share a room with another worker than if they work alone. This is consistent with the hypothesis that the workers derive status from their relative productivity. This suggests that there is, by analogy, a possibility for individuals to derive status from their working time. Their results are also in line with an individual utility function that is concave in status: They find that sharing a room with another worker seems to increase productivity more for workers who are less productive. One can imagine that the increase in productivity is larger because the increase in status is also larger for those who lag further behind their peers in terms of productivity and therefore status. In the conspicuous work model, we have $U_{s}>0$ and therefore $U_{\bar{h}}<0$.

Clark and Oswald (1998) show that if individual utility functions are concave in social comparisons, those seeking status will tend to conform to the behaviour of others. This has the interesting implication that both conspicuous leisure and conspicuous work will lead to following behaviour in labour supply. In terms of the labour supply function presented above, we have $H_{\bar{h}}>0$ in the conspicuous leisure case, because if an individual's peers reduce their working time, the individual would need to reduce his as well to maintain his relative leisure position. Conversely, if his peers increase their working time, he can afford to increase his without losing status from conspicuous leisure while increasing the utility he derives from consumption through increased income from work.

In the case of conspicuous work, we also have $H_{\bar{h}}>0$ : If an individual's peers increase their working time, the individual will imitate them to maintain the status he derives from conspicuous work. The labour supply of his peers motivates a man to work more hours to improve his relative working time position. The working time of his peers influences his behaviour because of his preference for the status of a 'hard worker'.

To sum up, all three models of social interactions in labour supply predict a positive effect of peer working time on individual working time, but for different reasons, associated with different roles of peer working time in the individual utility function.

\subsection{Peer effects in working time: empirical evidence and link with happiness}

\subsubsection{Empirical evidence of peer effects in working time}

There is evidence that individuals conform to the labour supply of those around them. Peer labour supply has been found to have an influence on mothers' labour market participation (Maurin and Moschion, 2009), exit rates from welfare programmes (Van der Klaauw and Van Ours, 2003), exit from unemployment (Topa, 2001), and effort provision of workers (Ichino and Maggi, 2000; Falk and Ichino, 2006). As far as the number of hours worked is concerned, various studies find evidence of peer effects. Woittiez and Kapteyn (1998) find that, for married women in the Netherlands, the desired number of hours worked is influenced by the working time of a peer group constructed on the basis of the characteristics of the women themselves and the characteristics of their peers as reported by these women. Aronsson et al. (1999) find that the number of hours worked by Swedish married men is influenced by the number of hours worked in a social reference group defined on the basis of age, educational level, and the presence of children in the household. Weinberg et al. (2004) find that the male employment rate in the neighbourhood influences the annual number of hours worked by young American men. Grodner and Kniesner (2008) construct a peer group based on a measure of economic proximity and find that this peer group's working time is positively related to the working time of married American men.

The estimation of peer effects raises, however, a number of methodological problems. First, most studies examining the effect of peer behaviour on labour supply have to make strong assumptions about the peer group. The studies about peer effects in working time mentioned above mainly construct peer groups based on demographic and/or geographic criteria. The only exception is the study of Woittiez and Kapteyn (1998), who construct their measure of peer working time using information provided by the respondents about whom they consider to be their peer group. Soetevent (2006, p. 222) regrets that this strategy 'was since then not copied by other researchers'. To our knowledge, subjective data about peer groups has still not been used in more recent years to estimate peer effects on labour supply.

A second problem is that one has to find a strategy to distinguish effects really caused by peer behaviour from what Manski (1993) calls correlated effects, that is, effects that are simply due to the fact that individuals and their peers share unobserved characteristics or that they are affected by the same environmental factors or shocks. Aronsson et al. (1999) use cohort fixed effects to account for changes in the preferences of the reference group as a whole, which enables them to control for time-invariant shared unobservables, but not for common shocks or shared unobserv- 
Table 1

\begin{tabular}{lrrrrr}
\hline Descriptive statistics. & \multicolumn{1}{c}{ Mean } & \multicolumn{1}{c}{ SD } & Min. & Max. & N \\
\hline Variable & 4.03 & 0.626 & 1 & 5 & 8203 \\
Happiness & 31,581 & 14,685 & 454 & 111,473 & 8203 \\
Net household income & 7.499 & 1.368 & 1 & 11 & 8203 \\
Weekly hours & 41.653 & 9.137 & 1 & 72 & 8203 \\
Male peers' weekly hours & 39.628 & 5.49 & 1 & 70 & 8203 \\
Looking for another job & 0.195 & 0.397 & 0 & 1 & 8203 \\
Subjective health & 4.064 & 0.636 & 1 & 5 & 8203 \\
Age & 43.958 & 9.083 & 23 & 60 & 8203 \\
Number of children & 1.107 & 1.19 & 0 & 6 & 8203 \\
Partner & 0.827 & 0.378 & 0 & 1 & 8203 \\
\hline
\end{tabular}

ables that would vary over time. Grodner and Kniesner (2008) instrument the mean labour supply of a reference group using the mean labour supply in the adjacent reference group. For this technique to solve the problems mentioned, they have to assume that the labour supply in this adjacent reference group is not correlated with an individual's own labour supply, that is, no unobservables or common shocks are shared with this adjacent group and the mean labour supply of this adjacent group has no direct influence on men's own labour supply. Finally, Weinberg et al. (2004) use individual fixed effects and individual-specific experience profiles to correct for the influence of shared unobservables, both time invariant and time varying, but they cannot entirely rule out the effect of common shocks.

From the literature, we can conclude that there is evidence that a man's working time is influenced by the labour supply of his environment, even if not all methodological problems have been resolved yet. Understanding the potential mechanisms behind such peer effects could help us to better understand whether and how peer working time actually influences individual working time.

\subsubsection{Peer working time and happiness}

Peer influences, or social influences in general, are often mentioned in the literature as one of the possible drivers behind the link between working time and subjective well-being: 'Social custom and conditioning might affect subjective well-being and the gender division of labour' (Booth and Van Ours, 2008, p. F79); 'Men might be more satisfied with longer working hours because the social norm is to work full-time' (Rätzel, 2009, p. 21). Booth and Van Ours (2009) explain their finding that working full-time is positively associated with the life satisfaction of men and negatively associated with that of women by traditional gender identities. However, to our knowledge, the way in which peer working time influences individual well-being has not yet been examined.

In this paper, we examine the link between peer working time and happiness to obtain a better picture of an individual's utility function. We are aware of the fact that self-reported happiness is only an imperfect proxy for utility, since individuals make mistakes in predicting their happiness when they make decisions (Kahneman and Thaler, 2006) and sometimes even seem to consciously choose something else than maximizing their happiness (Benjamin et al., 2012). Still, we believe that self-reported happiness and utility are sufficiently correlated for an analysis of happiness to yield interesting insights into characteristics of the utility function. Happiness data are used to study potential imitative behaviour by Oswald and Powdthavee (2007) and Blanchflower et al. (2009), who apply the model of Clark and Oswald (1998) to the case of obesity. They show that relative weight influences individual happiness and that this could lead to imitative obesity. We build on these contributions and test the model of Clark and Oswald (1998) along with two concurrent models in the case of relative labour supply.

\section{Data}

\subsection{The CentER data panel}

We use the CentER data panel, a panel survey held since 1993 among Dutch households. The estimation sample consists of men aged 23-60 surveyed in the years $1994-2011$. $^{6}$ Table 1 presents descriptive statistics for the main variables in our estimation sample.

We choose to focus on individuals with a positive weekly working time, unlike Booth and Van Ours (2008, 2009, 2013), because we want to determine the effects of weekly working time and would like to avoid picking up any effect of being employed rather than unemployed. To rule out any effect on happiness of being employed while one's peers are unemployed, we also exclude individuals who report zero as the average working time of their peers and those who indicate that most of their peers do not have a paid job. $^{7}$

The number of hours that respondents work is measured by a number of questions with respect to their normal (contractual) weekly working hours, their usual working hours, and any additional hours they work in a second job. To measure weekly working time, we add up the usual number of hours and hours worked in second jobs. The happiness of respondents was measured by their response to the question: 'All in all, to what extent do you consider yourself a happy person?', to which they could answer using a 5-point scale ranging from 'very happy' to 'very unhappy'. Fig. A.1 presents histograms of the distributions of the happiness and hours variables that are central to the analysis.

\subsection{Reports about peers and their reliability}

The questions about an individual's peers were introduced as follows: 'The following questions concern your circle of acquaintances, that is, the people with whom you associate frequently, such as friends, neighbours, acquaintances, or maybe people at work'. A series of questions follows about the age of most of the respondent's acquaintances (in five-year age groups), the number of persons in the household of most of these acquaintances, the average total net income per year of those households (in 11 categories, see Table C.1), the level of education of most acquaintances

\footnotetext{
${ }^{6}$ We focus on men, as do Aronsson et al. (1999), Weinberg et al. (2004), Grodner and Kniesner (2008), because the distribution of their working hours is quite strongly concentrated around a full-time workweek, while there is much more variation in the weekly working times of women. This raises the question which role social norms and peer effects play among men. First results about women suggest that peer working time does not influence their labour supply and happiness. Further investigation of this is left for future research. We follow Booth and Van Ours (2013) for the age interval.

${ }^{7}$ In the robustness checks in Sections 4.1 and 4.2, we show that including non-working individuals and those with non-working peers does not substantially change the results.

8 Those who answered that they 'don't know' were excluded from the sample. They represent less than $1 \%$ of the sample.
} 


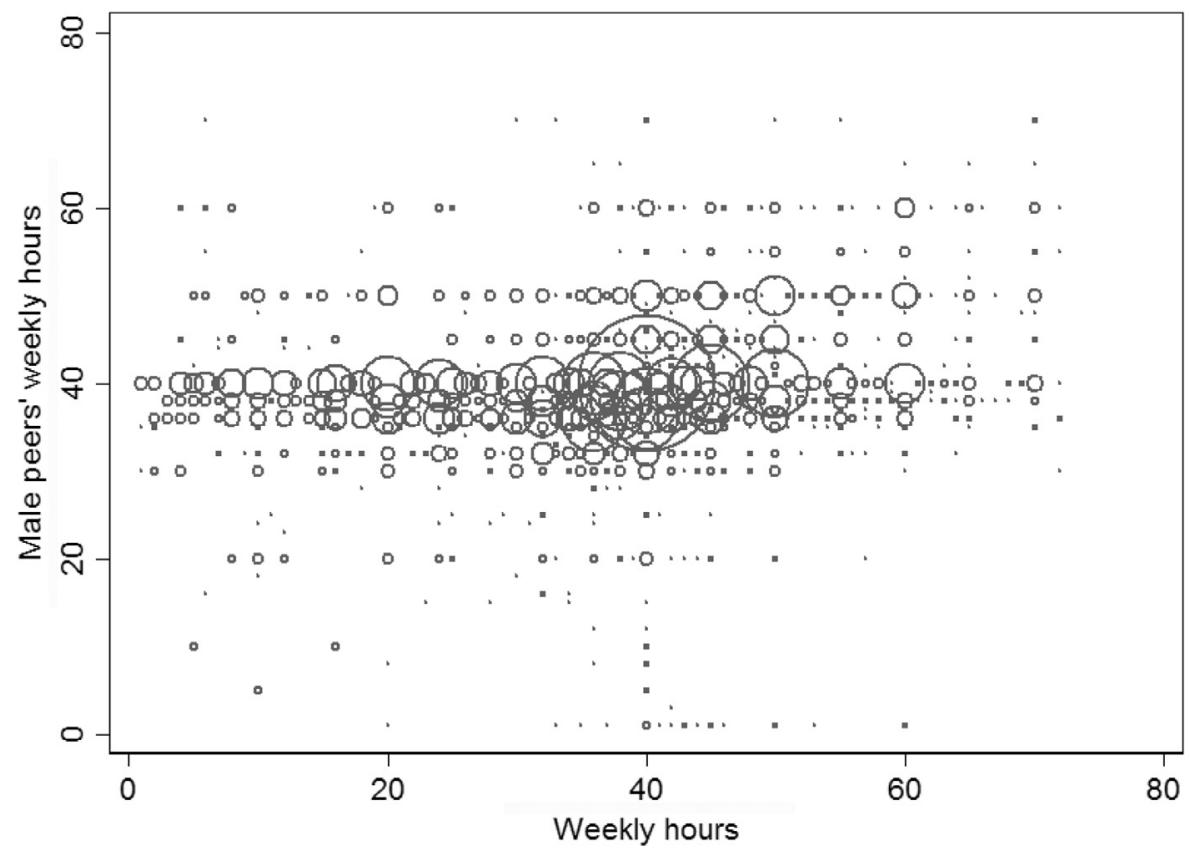

Fig. 1. Scatterplot of peer hours against own hours.

(in seven categories), and the kind of employment of most acquaintances. The labour supply of the people in the respondents' environment is measured using two separate questions for men and women, formulated as follows: 'If you think of the men among your acquaintances, how many hours per week do they work on average?'.

The Tables C.2 and Table C.3 compare the demographic characteristics of men in our sample to those of their peers. The tables show that men in our sample are generally similar to their peers but that, as one could expect, not everyone classifies the majority of their peers as similar to themselves in terms of age, education level, household size, and so forth. This demonstrates that directly collecting information on peer characteristics has real added value.

However, answers to questions about peers, and reports of peer working time in particular, might be biased in different ways. First, respondents could use their own working time as a proxy for their peers', in which case reports about peer working time are not informative. Figure 1 shows how peer working time relates to an individual's own working time. The answers about peer working time are concentrated along horizontal lines, which seems to indicate that the respondents used the focal points constituted by a number of standard weekly work durations (e.g. 30, 36, 38, 40, 45, 50 , and $60 \mathrm{~h}){ }^{9}$ If individuals would use their own working time as a proxy for their peers' working time, most observations would be concentrated on the 45-degree line. We see that this is not the case, which is reassuring.

Second, some general characteristics of individuals (e.g. selfconfidence) are likely to influence both their happiness and the way they perceive their peers' working time. However, the panel structure of the data enables us to clean out the effect of any such time-invariant characteristic.

\footnotetext{
${ }^{9}$ In particular, there is a mass point at $40 \mathrm{~h}$ for peer working time (see Fig. A.1). This suggests that respondents use this as an anchor if they see their peers as working full-time without overtime. To check whether this mass point influences our results, we also estimated our main models while including a dummy indicating whether peer working time was equal to 40 . Our results were not affected, showing that anchoring does not influence our results.
}

Third, one can think of time-varying factors which influence the way a respondent estimates his peers' working time as well as his labour supply and happiness. For instance, someone who works less than he would like might both be less happy and overestimate the working time of his peers. Then, the negative effect of peer working time on happiness will be overestimated. We show that this does not seem to be the case by controlling for over- and underemployment in Section 4.2.3. Admittedly, we cannot entirely exclude the possibility that other changes occur in the individual's life which influence his happiness and labour supply as well as his reports about peer working time. Moreover, a respondent's happiness level might influence his reports about his peers. The interpretation of our results below as an effect of peer working time on own labour supply and own happiness is subject to the assumption that these possibilities are either not realized or do not play an important role.

One way to check the reliability of respondents' reports about their peers is to compare the relations among reported peer characteristics with the relations among the same set of own characteristics. If these relations are similar, this gives us some confidence that reports about peer characteristics are not severely biased by the respondents' own characteristics or situation. Table C.4 presents the estimation results of regressions of peer household income and male peers' working hours on the other peer characteristics measured in the survey, next to regressions of the respondent's own household income and own weekly working hours on own characteristics. In both regressions, all variables are standardized to correct for the fact that variables concerning the respondent and variables concerning his peers are often measured on different scales. Overall, the coefficients on own characteristics and those on peer characteristics have the same order of magnitude. The differences in coefficients on the age variables may be due to the fact that the age range is limited for the respondents themselves in our sample, while the age range for their peers is not. For many variables (household size, education level, hours worked, household income), the confidence intervals overlap. This is reassuring, as it suggests that there are no severe biases in answers 
Table 2

Weekly hours worked: OLS model with fixed-effects.

\begin{tabular}{llll}
\hline & $(1)$ & $(2)$ & $(3)$ \\
\hline Male peers' weekly hours & & $0.0999^{* * *}$ & $\begin{array}{l}0.0939^{* * *} \\
(0.0288)\end{array}$ \\
Log net peer household income & & $(0.0285)$ & 0.5682 \\
& & & $(0.5811)$ \\
Age & $0.8885^{* * *}$ & $0.8695^{* * *}$ & $0.8529^{* * *}$ \\
& $(0.2721)$ & $(0.2696)$ & $(0.2703)$ \\
Age ${ }^{2}$ & $-0.0113^{* * *}$ & $-0.0110^{* * *}$ & $-0.0109^{* * *}$ \\
& $(0.0029)$ & $(0.0029)$ & $(0.0029)$ \\
Number of children & -0.1005 & -0.0977 & -0.0999 \\
& $(0.2670)$ & $(0.2592)$ & $(0.2601)$ \\
Partner & 0.4684 & 0.4310 & 0.3965 \\
& $(0.7843)$ & $(0.7826)$ & $(0.7815)$ \\
Constant & $25.0427^{* * *}$ & $21.1676^{* * *}$ & $20.8889^{* * *}$ \\
& $(6.1088)$ & $(6.3047)$ & $(6.3241)$ \\
Observations & 8203 & 8203 & 8203 \\
Individuals & 3042 & 3042 & 3042 \\
$R^{2}$ & 0.02 & 0.03 & 0.03 \\
\hline
\end{tabular}

Standard errors (clustered by individual) in parentheses; ${ }^{*} p<0.1$; ${ }^{* *} p<0.05$;

*** $p<0.01$; Year dummies included as additional controls.

about peers. We lose about a quarter of the observations on working men aged 23 to 60 due to non-response on the peer labour supply questions. Using the test designed by Wooldridge (1995), we find that this does not lead to selection bias in our estimates (results available from the authors). The response to the question about the average income of the respondent's acquaintances is lower (only about 50\%) than for other items relating to peers. To avoid losing too many observations, we predicted the missing values for peer income as the linear prediction resulting from estimation of an ordered logit model with measured peer income as the dependent variable and measured peer characteristics as the independent variables (see Appendix B for more information about the prediction of peer income and about the cleaning of the data).

\section{Estimations}

\subsection{Peer working time and individuals' own working time}

All three models of social interactions in labour supply discussed above predict that the relation between individuals' own and peer working time should be positive. Therefore, we start by estimating this relation.

\subsubsection{Estimation method}

We estimate a fixed effects model. This is useful not only to control for unobserved heterogeneity among individuals but also, more importantly, to take into account unobserved characteristics that individuals can share with their peers and which can account for part of a positive relation between their own and peer working time. The standard errors are clustered at the individual level.

We do not observe hourly wages directly. Computing the hourly wage on the basis of total earnings and hours worked would cause a bias in its coefficients, since hours worked is the dependent variable in our analysis. Therefore, we follow Weinberg et al. (2004) by estimating a reduced form of the labour supply equation that does not include hourly wage. ${ }^{10}$

\subsubsection{Estimation results}

Table 2 presents the estimation results.

We first estimate a baseline model that does not include peer working time (column 1). Peer working time is added to this baseline model in column 2. The coefficient on the working time of

\footnotetext{
10 Including hourly wage and non-earned income as regressors in the model does not cause the coefficient on peer working time to change.
}

male peers is positive and statistically significant. It is however small (one additional hour worked by peers corresponds to 6 more minutes worked by the individual), which suggests that individuals tend to follow the labour supply of their peers without engaging in an explosive rat race. The working time of female peers, when included in the model, is not significant (results available from the authors). In addition, including the hours worked by the individual's partner does not affect the coefficient on peer working time (results available from the authors). The coefficient on peer working time remains positive and even hardly changes when peer income is added to the model as a regressor (column 3). ${ }^{11}$

Our results are in line with evidence of peer effects on working time found in earlier studies. In their estimation of peer effects on labour supply, Woittiez and Kapteyn (1998) and Grodner and Kniesner (2008) include a lag of individuals' own working time to control for habit formation in the labour supply. Following their example (see column 1 of Table C.5), we find that habit formation indeed plays a role, but that the coefficient on peer working time remains virtually unchanged. ${ }^{12}$

\subsubsection{Robustness checks}

We estimate a number of additional models to check for the role of various potential sources of bias in our estimation results. Table 3 presents an overview of the results of various robustness checks we conducted. The fixed effects baseline model reproduced in row 0 of the table is the point of reference.

1. First, we want to examine the role of possible feedback effects from the individual's own working time to peer working time (endogenous effects in Manski's (1993) terminology). Therefore, we also estimate the model replacing the present value of peer working time by its one-year lagged value. The estimation results are presented in column 2 of Table C.5. The coefficient on the lag of peer working time is still positive and significant. ${ }^{13}$

2. Second, to account for what Manski calls exogenous effects, we check whether observable characteristics of peers other than their working time have an influence on an individual's working time. We include the peer characteristics that are measured in our dataset as additional regressors in the model. The estimation results are presented in column 3 of Table C.5. We find that most added peer characteristics have no significant influence on an individual's working time. Most importantly, controlling for additional peer characteristics does not affect the coefficient on peer working time much.

3. Third, we argued above that estimating a fixed effects model eliminates the role of time-invariant characteristics that individuals might share with their peers and which might influence both their peers' and their own working time. To check this argument, we compare our estimates with those of a pooled model in Table C.6. This table shows that the coefficient on peer working time is indeed four times larger in pooled estimations, which confirms that using fixed effects corrects for the role of confounding factors.

4. Then, a man's working time and that of his peers can both be determined by external factors, such as labour demand. We therefore estimate a model in which the dependent variable is no longer actual hours worked but, instead, the man's desired

\footnotetext{
11 The coefficient on peer income, however, is larger when peer hours are not included in the model.

12 We are aware that including a lag of the dependent variable as a regressor in a fixed effects model leads to bias (Nickell, 1981). In a pooled model, the coefficient on peer working time drops by half when lagged individual's own hours are included, but both variables remain significant at the $1 \%$ level.

${ }^{13}$ Individuals can change peers over time. We assume that the peer group does not change much from one year to another and, also, that the working time of peers does not change much. Further lags of peer working time were not significant.
} 
Table 3

Overview of robustness checks for the weekly hours estimations.

\begin{tabular}{|c|c|c|c|}
\hline & Potential source of bias & Estimation method & Coefficient on peer working time \\
\hline 0 & & Fixed-effects model (baseline) & $0.0939 * * *$ \\
\hline 1 & Reverse causality (Endogenous effects) & Use lag of peer working time & $0.0611^{* *}$ \\
\hline 2 & $\begin{array}{l}\text { Influence of other peer characteristics } \\
\text { (Exogenous effects) }\end{array}$ & Control for other observed peer characteristics & $0.0857 * * *$ \\
\hline 3 & $\begin{array}{l}\text { Time-invariant unobservables } \\
\quad(\text { Correlated effects } 1)\end{array}$ & $\begin{array}{l}\text { Pooled model for comparison with fixed-effects } \\
\text { model }\end{array}$ & $0.4158^{* * *}$ \\
\hline 4 & $\begin{array}{l}\text { Common shocks (e.g. in labour } \\
\text { demand) (Correlated effects 2) }\end{array}$ & Desired working time as dependent variable & $0.0677^{*}$ \\
\hline 5 & Endogenous controls & Drop potentially endogenous controls & $0.1001^{* * *}$ \\
\hline 6 & Potentially asymmetric effect & $\begin{array}{l}\text { Include interaction with dummies for increase } \\
\text { and decrease in peer working hours }\end{array}$ & Decrease: $0.097^{* *}$ Increase: $0.091^{* * *}$ \\
\hline
\end{tabular}

working time ${ }^{14}$ (Table C.7), because the desired working time is less likely to be influenced by labour demand conditions than the actual working time. The estimation results show that peer working time still has a positive influence on desired working time. This suggests that the positive relation is not purely driven by demand factors.

5. Next, for the reader worried about the potential endogeneity of control variables such as peer income, having a partner, or the number of children, we also re-estimated our model leaving out these control variables. The main results were not affected (see Table 3; full results available from the authors).

6. It is also important to check whether men's labour supply reacts in the same way to an increase and a decrease in peer working time. The main model presented in Table 2 assumes that the reaction has the same absolute value in both cases. In order to check whether this is the case, we include in the model interactions of peers' working hours with dummies indicating whether peers' working hours increased or decreased compared to the year before. The estimation results are reported in Table C.8. The effect of a decrease in peer working time seems to be slightly larger than the effect of an increase, but the difference is not statistically significant.

Finally, the reader might be worried about selection bias, because we estimate a labour supply model using only working individuals with working peers. However, when we remove the restriction of the positive individual's own and peer working time on our sample, the sample size increases only to $n=9261$, with 3346 individuals. This means that about $90 \%$ of individuals in our sample work and have peers who work. The chances of selection bias are therefore very limited.

To sum up, we have addressed the role of time-invariant characteristics shared with peers, labour demand conditions, reverse causality (feedback effects), and selection bias. ${ }^{15}$ All in all, we consider the results of these robustness checks to be evidence that peer working time has a positive influence on a man's own working time. This is consistent with any of the models presented above in which peer working time enters the agent's utility function. In the following section, we want to discriminate between these concurrent models by turning to the link between peer working time and happiness.

\footnotetext{
14 The question about desired hours is phrased as follows: 'How many hours per week WOULD YOU LIKE to work in total? If you have more than one job, give the sum total for all jobs'.

15 To try and tackle any potential remaining issues, we also estimated a model in which we instrumented for peer working time using peer age as an instrument. The effect of peer working time became so imprecisely estimated that it could not be statistically distinguished from zero. Consequently, the Hausman test did not reject the null hypothesis of exogeneity of peer working time. Overall, the evidence yielded by instrumenting peer working time was inconclusive.
}

\subsection{Peer working time and happiness}

\subsubsection{Estimation method}

In this section, we study the relation between peer working time and happiness of male workers. Earlier research has demonstrated that in studies of self-reported happiness, it is crucial to take individual fixed effects into account (e.g. Lykken and Tellegen, 1996). Moreover, individual fixed effects offer a partial solution to the problem of potential endogeneity of an individual's own and peer working time. If individuals share some time-invariant characteristics with their peers that influence both working time and happiness, not controlling for them could bias the coefficient of peer working time.

For simplicity, we estimate a linear model with fixed effects. Because our dependent variable is discrete, we also estimate ordered logit models with individual fixed effects for comparison purposes. Using both the method of Ferrer-i Carbonell and Frijters (2004) (FCF) and the 'blow-up and cluster' (BUC) method of Baetschmann et al. (2015), ${ }^{16}$ we find, as Ferrer-i Carbonell and Frijters (2004), that the estimation results are not substantially different when using ordered logits with fixed effects (see Table C.9).

\subsubsection{Estimation results}

Table 4 presents the estimation results.

In column 1, we estimate a model without peer working time as a baseline model for comparison purposes. To allow for possible non-linear effects of hours on happiness, the estimation includes a quadratic term for weekly hours. ${ }^{17}$

In columns 2 to 5 , we test the three models of social interactions presented in Section 2 by examining how peer working time relates to individual happiness. Column 2 presents a test of the externalities hypothesis by including the interaction of a man's own working time with his peers'. If individuals enjoy working more when their peers work more hours, one would expect a positive sign on the coefficient of the interaction term. This is not the case here. The coefficient is negative, very small, and statistically insignificant, which seems to invalidate the externalities hypothesis. ${ }^{18}$

To test the conformity model, we include the square of the difference between a man's working time and the weekly hours of his peers (column 3). One would expect the coefficient on this vari-

\footnotetext{
16 We are thankful to Andy Dickerson for providing us with his code (Hole et al., 2011).

17 In column 1, happiness is found to peak at 51 hours per week. In the other columns, the optimal number of own weekly working hours ranges from 44 to 53 , except for column 2 where the inclusion of the interaction term with peer working time changes the interpretation of the coefficients on own working time variables. The effect of weekly hours on happiness is likely to be overestimated because own working time is not exogenous.

18 The interaction term is not significant either in a model including only a linear hours term.
} 
Table 4

Happiness: OLS model with fixed-effects.

\begin{tabular}{|c|c|c|c|c|c|}
\hline & (1) & $(2)$ & (3) & $(4)$ & $(5)$ \\
\hline Weekly hours & $\begin{array}{l}0.0094^{* *} \\
(0.0042)\end{array}$ & $\begin{array}{l}0.0174^{* *} \\
(0.0088)\end{array}$ & $\begin{array}{l}0.0197^{* * *} \\
(0.0063)\end{array}$ & $\begin{array}{l}0.0096 * * \\
(0.0042)\end{array}$ & $\begin{array}{l}0.0071 \\
(0.0044)\end{array}$ \\
\hline Weekly hours ${ }^{2}$ & $\begin{array}{l}-0.0001^{*} \\
(0.0000)\end{array}$ & $\begin{array}{l}-0.0001 \\
(0.0000)\end{array}$ & $\begin{array}{l}-0.0002^{* * *} \\
(0.0001)\end{array}$ & $\begin{array}{l}-0.0001^{*} \\
(0.0000)\end{array}$ & $\begin{array}{l}-0.0001 \\
(0.0001)\end{array}$ \\
\hline Own hours * peer hours & & $\begin{array}{l}-0.0002 \\
(0.0002)\end{array}$ & & & \\
\hline$\left(\right.$ Own hours - peer hours) ${ }^{2}$ & & & $\begin{array}{l}0.0002^{* *} \\
(0.0001)\end{array}$ & & \\
\hline Male peers' weekly hours & & $\begin{array}{l}0.0059 \\
(0.0092)\end{array}$ & & $\begin{array}{l}-0.0041^{* *} \\
(0.0020)\end{array}$ & \\
\hline Working less than peers & & & & & $\begin{array}{l}-0.0492^{* *} \\
(0.0239)\end{array}$ \\
\hline Working more than peers & & & & & $\begin{array}{l}-0.0048 \\
(0.0187)\end{array}$ \\
\hline Log net household income & $\begin{array}{l}0.0264^{*} \\
(0.0147)\end{array}$ & $\begin{array}{l}0.0256^{*} \\
(0.0146)\end{array}$ & $\begin{array}{l}0.0255^{*} \\
(0.0148)\end{array}$ & $\begin{array}{l}0.0263^{*} \\
(0.0147)\end{array}$ & $\begin{array}{l}0.0269 * \\
(0.0147)\end{array}$ \\
\hline Log net peer household income & $\begin{array}{l}-0.0676 \\
(0.0438)\end{array}$ & $\begin{array}{l}-0.0387 \\
(0.0440)\end{array}$ & $\begin{array}{l}-0.0332 \\
(0.0447)\end{array}$ & $\begin{array}{l}-0.0438 \\
(0.0442)\end{array}$ & $\begin{array}{l}-0.0641 \\
(0.0442)\end{array}$ \\
\hline Looking for another job & $\begin{array}{l}-0.0527^{* * *} \\
(0.0198)\end{array}$ & $\begin{array}{l}-0.0535^{* * *} \\
(0.0197)\end{array}$ & $\begin{array}{l}-0.0531^{* * *} \\
(0.0198)\end{array}$ & $\begin{array}{l}-0.0527^{* * *} \\
(0.0197)\end{array}$ & $\begin{array}{l}-0.0519^{* * *} \\
(0.0197)\end{array}$ \\
\hline Subjective health & $\begin{array}{l}0.0819^{* * * *} \\
(0.0154)\end{array}$ & $\begin{array}{l}0.0825^{* * *} \\
(0.0154)\end{array}$ & $\begin{array}{l}0.0818^{* * * *} \\
(0.0154)\end{array}$ & $\begin{array}{l}0.0824^{* * * *} \\
(0.0154)\end{array}$ & $\begin{array}{l}0.0823^{* * * *} \\
(0.0154)\end{array}$ \\
\hline Age & $\begin{array}{l}-0.0330 \\
(0.0204)\end{array}$ & $\begin{array}{l}-0.0338^{*} \\
(0.0204)\end{array}$ & $\begin{array}{l}-0.0344^{*} \\
(0.0204)\end{array}$ & $\begin{array}{l}-0.0332 \\
(0.0204)\end{array}$ & $\begin{array}{l}-0.0329 \\
(0.0204)\end{array}$ \\
\hline Age $^{2}$ & $\begin{array}{l}0.0004^{*} \\
(0.0002)\end{array}$ & $\begin{array}{l}0.0004^{*} \\
(0.0002)\end{array}$ & $\begin{array}{l}0.0004^{*} \\
(0.0002)\end{array}$ & $\begin{array}{l}0.0004^{*} \\
(0.0002)\end{array}$ & $\begin{array}{l}0.0004^{*} \\
(0.0002)\end{array}$ \\
\hline Number of children & $\begin{array}{l}-0.0036 \\
(0.0206)\end{array}$ & $\begin{array}{l}-0.0026 \\
(0.0205)\end{array}$ & $\begin{array}{l}-0.0029 \\
(0.0205)\end{array}$ & $\begin{array}{l}-0.0038 \\
(0.0207)\end{array}$ & $\begin{array}{l}-0.0032 \\
(0.0207)\end{array}$ \\
\hline Partner & $\begin{array}{l}0.3195^{* * *} \\
(0.0862)\end{array}$ & $\begin{array}{l}0.3194 * * * \\
(0.0863)\end{array}$ & $\begin{array}{l}0.3191^{* * *} \\
(0.0863)\end{array}$ & $\begin{array}{l}0.3194^{* * *} \\
(0.0863)\end{array}$ & $\begin{array}{l}0.3214^{* * *} \\
(0.0862)\end{array}$ \\
\hline Constant & $\begin{array}{l}3.7044^{* * *} \\
(0.5005)\end{array}$ & $\begin{array}{l}3.4848^{* * *} \\
(0.6324)\end{array}$ & $\begin{array}{l}3.4890^{* * * *} \\
(0.5151)\end{array}$ & $\begin{array}{l}3.8357^{* * *} \\
(0.5099)\end{array}$ & $\begin{array}{l}3.7623^{* * *} \\
(0.5015)\end{array}$ \\
\hline Observations & 8203 & 8203 & 8203 & 8203 & 8203 \\
\hline Individuals & 3042 & 3042 & 3042 & 3042 & 3042 \\
\hline $\mathrm{R}^{2}$ & 0.035 & 0.037 & 0.037 & 0.037 & 0.036 \\
\hline
\end{tabular}

Standard errors (clustered by individual) in parentheses; ${ }^{*} p<0.1$; ${ }^{* *} p<0.05$; ${ }^{* *} p<0.01$; Year dummies included as additional controls.

able to be negative if men dislike having a working time that differs too much from that of their peers. However, the coefficient is positive and very small even if statistically significant, which is at odds with the idea that men conform to their peers' working time because of a preference for conformity.

In column 4 , we test the status model by introducing male peer working time into the regression. Note that this is practically equivalent to introducing the difference between an individual's own and peer working time, since we already control for the individual's own working time. Conspicuous leisure would imply a positive coefficient on peer working time, while the conspicuous work model would predict the opposite. Peer working time appears to be negatively associated with happiness, therefore supporting the latter model. ${ }^{19}$ The coefficient is statistically significant, although the effect size is small. One additional hour of peer working time corresponds to a drop in happiness by $0.6 \%$ of a standard deviation. ${ }^{20}$ Interestingly, only the working time of male peers is

\footnotetext{
${ }^{19}$ We also tried including the ratio of one's own weekly hours to peer weekly hours, to test the ratio comparison version of the model. This lead to similar results, i.e. the coefficient on the ratio is positive and statistically significant. We also estimated a model including the squared value of male peers' working hours. In this model, the relation between peer working time and happiness appeared to be negative for peer hours below 65 hours per week. (All results available from the authors.)

20 An additional hour of peer working time seems to be equivalent to a drop by $15 \%$ in household income. However, the coefficient on household income is unusually small compared to studies based on other data. If we used the coefficient on household income in the study of Ferrer-i Carbonell and Frijters (2004), an additional hour of peer working time would correspond to a drop in household income by about $7.5 \%$.
}

significantly associated with men's happiness. The working time of female peers is not significant when taken up in the regression (results available from the authors).

Our results suggest that relative working time can be a source of status for male workers. Clark and Oswald (1998) show that if utility is concave in status, individuals will tend to follow the behaviour of their peers. The positive relation found between a man's own working time and the number of hours worked by his peers suggests that this should be the case here. We test for this in column 5. Here, we create dummies for working fewer hours than peers, the same number of hours, or more hours. We classify an individual as working the same number of hours as his peers if the absolute value of the difference between his peers' working time and his own is two hours or less. The results indicate that working less than one's peers is negatively related to a man's happiness, while working more is not significantly related to happiness. This is in line with the idea of a concave relationship between status, measured as the difference between a man's own hours and his peers' hours, and utility. ${ }^{21}$ The model specification in column 5 is our preferred one, because the results are not sensitive to out-

\footnotetext{
21 We also estimated models with the log or a quadratic of status, measured as the difference between own and peer hours or the ratio of own to peer hours. However, the estimation results of these models were very sensitive to outliers, in particular to a limited number of observations for which the difference between own and peer working time takes extremely high values. Including a cubic term of the status variable in the model or running a local polynomial regression of happiness on status shows that the utility function is concave over the range of hours differences in which most observations are concentrated, but convex for especially high values of these differences in hours (results available from the authors).
} 
Table 5

Overview of robustness checks for the happiness estimations.

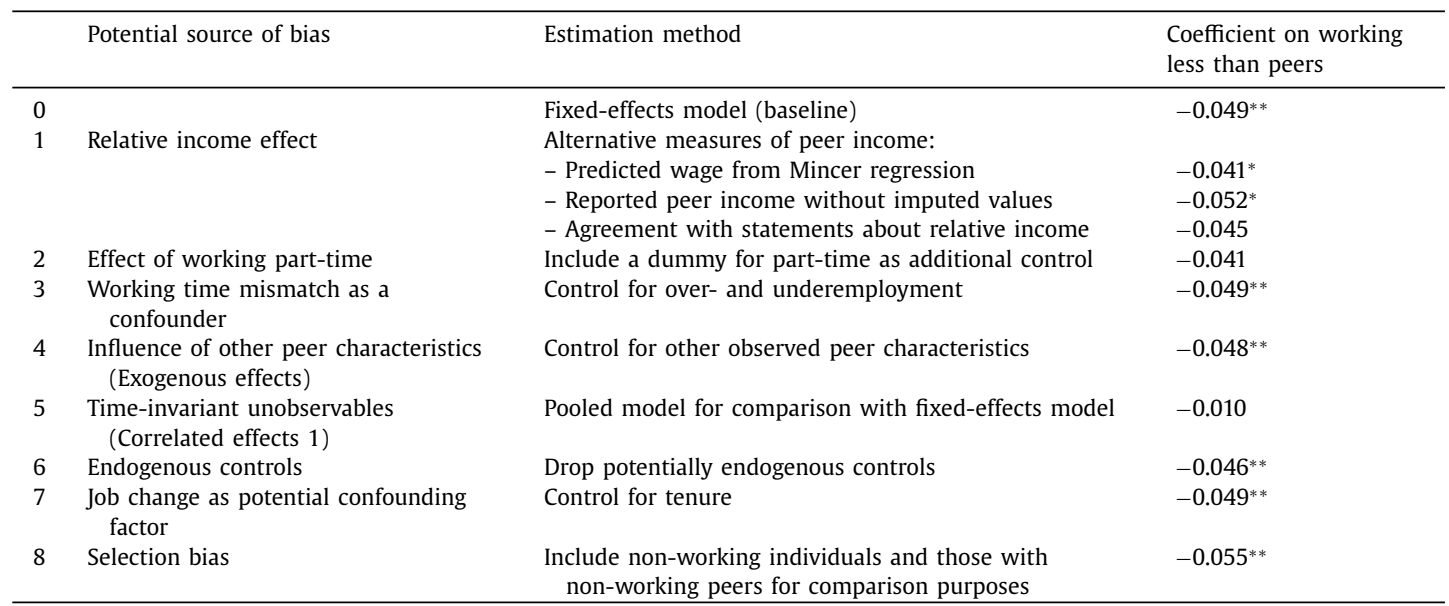

liers. Moreover, this specification does not favour either the additive or the ratio comparisons model, since working less than peers can represent either a negative difference between own and peer hours or a ratio of own to peer hours smaller than 1 . The size of the coefficient indicates that working less than one's peers is associated with a drop in happiness by about 0.05 points on a scale from 1 to 5 , i.e. about $8 \%$ of a standard deviation in happiness. Altogether, the results presented here explain why we find evidence of peer effects in our labour supply regressions, but only of very small magnitude. ${ }^{22}$

\subsubsection{Robustness checks}

We conduct a number of robustness checks to rule out factors that may cause a spurious relation between peer working time and happiness and to eliminate other potential sources of bias. All robustness checks are carried out on our preferred specification (column 5 in Table 4). ${ }^{23}$ Table 5 presents an overview of the robustness checks we conducted. For reference, the coefficient obtained in our preferred model is reproduced in row 0 of the table.

1. First, one might be worried that peer hours actually capture a relative income effect. Since we have a rather rough measure of peer income, which is imputed for a part of the estimation sample, the effect of peer hours could be a relative income effect that is not being captured by the peer income variable if peer hours are more precisely measured. ${ }^{24}$ To check for this possibility, we use three alternative measures of relative income. The estimation results are presented in Table C.10. In column 1, we estimate a version of the model in which the predicted wage from a Mincer regression is taken as the measure of peer household income. This predicted wage is a more precise measure of relative income (Clark and Oswald, 1996). The coefficient on working less than one's peers becomes a bit smaller, and statistical significance decreases (probably due to the drop in sample size), but the coefficient remains similar. In

\footnotetext{
22 We also estimated the model with job satisfaction and career satisfaction as dependent variables. Job satisfaction is negatively related to peer working time, and might therefore be a channel through which working less than peers affects happiness. Career satisfaction is not related to working less than peers. However, working more than peers is negatively related to both job and career satisfaction. This seems to suggest that the "job utility function" is different from the general utility function. A wish for conformity in working time may enter the former even if it is absent in the latter.

${ }^{23}$ We also conducted the same robustness checks on the model presented in column 4 of Table 4, and they led to the same conclusions.

24 The correlation coefficient between peer working time and peer income is 0.24 .
}

column 2, we estimate the model without imputed values of peer household income, in order to check whether the imputation of peer income introduces some error that would lead to overestimating the effect of peer hours. In this specification, the coefficient on the dummy for working less than peers is quite similar, although statistical significance is lower, probably due to the reduced sample size. This suggests that imputation of peer household income for some respondents does not bias our results. In column 3, we use an alternative for peer household income: the extent to which a respondent thinks his income is higher than that of others in his environment. Respondents of the CentER data panel were asked to rate their agreement with a number of general statements about their relative income. ${ }^{25}$ We compute an average measure based on the answers to these questions. The coefficient on working less than peers still remains similar, although statistical significance drops below the conventional thresholds due to the reduced sample size. Admittedly, the three alternative measures of relative income used here are also measured with error, and their relationship with happiness is either found to be weak or measured imprecisely. This means that one cannot entirely exclude the possibility that peer hours capture some part of a relative income effect. However, our results suggest that relative working time has an effect on happiness that goes beyond its impact on relative income. Still, a worker's relative working time could influence well-being because it is a predictor of good career perspectives and therefore of lifetime income (Landers et al., 1996) or because it is associated with consumption on the job (in the form of additional material benefits).

2. Second, because men who work less than their peers are likely to work part-time, the coefficient on peer weekly working time could capture the effect of working part-time on happiness. Booth and Van Ours $(2008,2009)$ have shown that full-time jobs maximize the happiness of men. To check for this possibility, we estimate the model including an additional dummy variable indicating whether the individual works part-time. ${ }^{26}$ The results are presented Table C.11. In the specification which includes peer working hours as a continuous variable (column

\footnotetext{
25 The statements were as follows: (1) "Compared to others in my environment, I am better off"; (2) "I think I have more assets than others in my environment"; (3) "Other people in my environment have more money to spend than I"; (4) "If I compare myself with my friends, I think in general I am financially better off"; (5) "I can spend more on durable consumer goods than others in my environment".

${ }^{26}$ Part-time is defined as 32 hours per week or less. Changing this definition does not lead to substantial changes in the results.
} 
1 ), working part-time is negatively and statistically significantly related to happiness, and the coefficient on peer working hours remains unchanged. In the specification containing dummies for working more or less than peers, the coefficients on these dummies and on the part-time dummy become a bit smaller and lose their statistical significance. This is probably due to the fact that the correlation coefficient between the dummy for working less than peers and for working part-time is very high (0.61). Still, the magnitude of the coefficient on working less than peers remains similar. Although it could be that working less than one's peers captures some of the effect of working part-time, we cannot conclude that working part-time explains away the negative effect of peer working hours for men.

3. Third, as mentioned in Section 3, working time mismatches may be a confounder of the relation between happiness and reports of peer working time. For instance, someone who would like to work more than he does may for that reason both be less happy and overestimate the working time of his peers. To rule out this source of bias, we control for over- and underemployment in the model. ${ }^{27}$ Estimation results are presented in Table C.12. Working time mismatches have a negative, very weak and statistically insignificant relation with happiness. Including these controls in the model leaves the coefficient on working less than peers virtually unchanged.

4. Next, as in the case of labour supply, we want to control for the influence of peer characteristics other than working time and income. We therefore estimate a model controlling for the peer characteristics that are measured in our dataset. The estimation results are presented in Table C.13. The coefficients on the additional controls are not significant and the coefficient on peer working time does not change, which indicates that exogenous effects do not bias our estimation results.

5. We argued above that the use of individual fixed effects eliminates potential time-invariant confounding factors. To check this argument, we also estimate a pooled version of our model (see Table C.14). The dummy for working less than peers turns out to be insignificant in the pooled model. This hints towards the presence of unobserved characteristics, possibly shared with peers, that would attenuate the negative relation between working less than peers and happiness. We conclude that what is negatively associated with happiness is not so much being an individual who works less than his peers, but rather getting to work less than one's peers, given all one's own and peer characteristics.

6. One might further be worried that other variables in the models estimated are endogenous (income, peer income, job satisfaction, health, partner, number of children) and that this endogeneity biases the coefficients on our variables of interest. However, when the model is estimated without these potentially endogenous control variables, the estimated coefficients on an individuals' own working time and working more or less than peers remain similar (full results available from the authors).

7. Another potential source of concern is the idea that a job change could affect one's own working time, peer working time, and happiness at the same time, therefore driving a spurious relation between these variables. We do not directly observe job changes in our data, but we can construct a measure of job tenure. Including this measure as a control in our model or a dummy for recent job changers (with job tenure shorter than a year or shorter than two years) does not affect the coef-

\footnotetext{
27 Overemployment is defined as the number of hours that a respondent actually works per week above his desired weekly working time. Underemployment is defined as the number of hours that a respondent would have to work more per week in order to meet his desired weekly working time.
}

ficient on one's own working time or on working more or less than peers (full results available from the authors).

8. For the reader worried that focusing on only working men with working peers might somehow distort the results, we also estimated our main models while including non-working men and men with non-working peers. The results remain similar (full results available from the authors). ${ }^{28}$

All robustness checks show that the negative coefficient on working less than peers that we found in our main model holds when we use different methods aiming at excluding different sources of spuriousness or bias. ${ }^{29}$ It has to be stressed, however, that both an individual's own working time and peer working time are measured by the respondents' answers to survey questions. Strictly speaking, we can therefore only say that men are less happy if they have the feeling that they work less than their male peers.

\section{Conclusions}

In this paper, we have correlated a unique measure of peer working time with both individual working time and individual happiness, to better understand how peer working time enters an individual's utility function. This enabled us to shed light on the drivers of peer effects in labour supply. We used the Dutch CentER panel and focused on men of working age. We used the respondents' answer to the question: 'If you think of the men among your acquaintances, how many hours per week do they work on average?'. A first descriptive look at the data confirms that the use of this unique measure of peer working time has added value compared with constructs based on individual characteristics, because individuals often report peer characteristics that differ from their own. Our results hinge on the assumption, supported by empirical findings, that biases in reports about peer working time do not play an important role in our data.

We presented three different models of the role peer working time can play in an individual's utility function. In the first model, individuals imitate their peers' labour supply because peer working time generates externalities for them that directly affect the marginal utility they obtain from work or leisure. In the second model, people derive utility from conforming to their peers' labour supply behaviour because the latter constitutes a social norm. In the third model, individuals derive status from the difference between their peers' working time and their own. This third model can take two forms: In the conspicuous leisure model, individuals derive status from working less than others because this is interpreted as evidence of affluence. On the contrary, in the conspicuous work model, status is derived from working a great deal and therefore individuals derive utility from working more or not working less than their peers. All three models predict a positive effect of peer labour supply on one's own labour supply, but they differ with respect to their predictions about the effect of peer working time on happiness.

\footnotetext{
28 In addition, the coefficient on peer income crosses the threshold for statistical significance, which is probably be due to increased power since we gain about a thousand observations.

${ }^{29}$ A further potential source of endogeneity could be reverse causality. It would play a role if being happy had an influence on the choice of working hours and the choice of peers. We attempted to tackle this problem by using instrumental variables for individuals' own and peer working hours as specified in column 4 of Table 4. As instruments for one's own working time, we used the constraints on the respondents' labour supply, measured as the difference between the desired weekly working time reported by the respondents and their actual weekly working time. The instrument we used for peer working time was peer age, but the F-statistic for the first stage indicated that it was not a very strong instrument. Peer working time, when instrumented, remained negative and significant. The endogeneity test could not reject the exogeneity of the working time variables.
} 
In line with all three models, we find evidence of peer effects on men's working time, in the sense that a man works more hours the longer his male peers work. This evidence is in line with the earlier results of Aronsson et al. (1999), Weinberg et al. (2004), and Grodner and Kniesner (2008). To distinguish between the three models, we studied the link between peer labour supply and happiness. We find that peer labour supply is negatively related to men's happiness, controlling for one's own working time, one's own income, and peer income, and in particular that men are less happy if they work less than their male peers. This finding is consistent with the conspicuous work model. The relations we find seem to be robust to a number of potential sources of bias or spuriousness.

Our results are in line with a conspicuous work model with comparison-concave utility (i.e. decreasing marginal utility of status), convex costs of working time, and non-increasing marginal private utility of working time (Clark and Oswald, 1998). A preference for status derived from work induces men to follow their peers' labour supply but, because of the decreasing marginal utility of status and the increasing marginal net costs of working more, they do not engage in an explosive rat race. It is worth noting that our results do not necessarily imply an increasing trend in working time at the macro level. The fact that individuals tend to follow their peers can also explain a downward trend in weekly working time. ${ }^{30}$ In the conspicuous work model, a decrease in peer working time (e.g. due to an external shock) allows men to decrease their own working time without losing status.

These results shed light on the motivations behind following behaviour in terms of working time. A better understanding of such motivations can be important for the design of incentives. For instance, Aronsson and Johansson-Stenman (2013) examine the implications for taxation of taking into account not only the role played by relative consumption, but also the implications of conspicuous leisure, and conclude that while conspicuous consumption calls for progressive taxation, conspicuous leisure would justify regressive taxation in some cases and not affect optimal taxation in others. Similarly, Mujcic and Frijters (2015) find evidence that individuals are motivated by conspicuous health on top of conspicuous consumption, which would call for lower marginal tax rates than conspicuous consumption alone would justify. If, as we find in this paper, individuals are motivated by conspicuous work, the case for progressive taxation becomes stronger again.

\section{Acknowledgements}

We thank Sarah Ayllón Gatnau, Andrew Clark, Jan Feld, Bert van Landeghem, Maarten Vendrik, and seminar participants at the EALE conference, Maastricht University, IARIW conference and Amsterdam Institute for Advanced Labour Studies for valuable comments and suggestions. This research has not been funded by any other organisation than the authors' employers.

\section{Supplementary material}

Supplementary material associated with this article can be found, in the online version, at 10.1016/j.socec.2017.04.002

\section{References}

Akerlof, G.A., 1980. A theory of social custom, of which unemployment may be one consequence. Q. J. Econ. 94 (4), 749-775.

\footnotetext{
30 In fact, on average, usual weekly hours worked by men on their main job decreased in the Netherlands from 38.1 hours in 1994 to 35.7 hours in 2011 (Organisation for Economic Co-operation and Development (OECD), stats.oecd.org) and also decreased during the same period for most other OECD countries.
}

Akerlof, G.A., Kranton, R.E., 2000. Economics and identity. Q. J. Econ. 115 (3), 715-753.

Alesina, A.F, Glaeser, E. Sacerdote, B, 2006. Work and leisure in the U.S and Europe why so different. In: Gertler, M., Rogoff, K. (Eds.), NBER Macroeconomics Annual 2005, vol. 20. MIT Press, pp. 1-100.

Aronsson, T., Blomquist, S., Sacklén, H., et al., 1999. Identifying interdependent behaviour in an empirical model of labour supply. J. Appl. Econ. 14 (6), 607626.

Aronsson, T., Granlund, D., 2015. Gender norms, work hours, and corrective taxation. J. Behav. Exp. Econ.s 56, 33-39. http://dx.doi.org/10.1016/j.socec.2015.03.001.

Aronsson, T., Johansson-Stenman, O., 2013. Conspicuous leisure: optimal income taxation when both relative consumption and relative leisure matter. Scand. J. Econ. 115 (1), 155-175.

Aronsson, T., Johansson-Stenman, O., 2014. Positional preferences in time and space: optimal income taxation with dynamic social comparisons. J. Econ. Behav. Organ. 101, 1-23.

Baetschmann, G., Staub, K.E. Winkelmann, R. 2015. Consistent estimation of the fixed effects ordered logit model. J. R. Statist. Soc. 178 (3), 685-703.

Benjamin, D.J., Kimball, M.S., Heffetz, O., Rees-Jones, A., 2012. What do you think would make you happier? what do you think you would choose? Am. Econ. Rev. 102 (5), 2083.

Bernheim, B.D., 1994. A theory of conformity. J. Polit. Econ. 102 (5), 841-877.

Blanchflower, D.G., Landeghem, B., Oswald, A.J., 2009. Imitative obesity and relative utility. J. Eur. Econ. Assoc. 7 (2-3), 528-538.

Booth, A.L., Van Ours, J.C., 2008. Job satisfaction and family happiness: the part-time work puzzle. Econ. J. 118 (526), F77-F99.

Booth, A.L., Van Ours, J.C., 2009. Hours of work and gender identity: does part-time work make the family happier? Economica 76 (301), 176-196.

Booth, A.L., Van Ours, J.C., 2013. Part-time jobs: what women want? J. Popul. Econ. 26 (1), 263-283.

Burda, M., Hamermesh, D.S., Weil, P., 2013. Total work and gender: facts and possible explanations. J. Popul. Econ. 26 (1), 239-261.

Ferrer-i Carbonell, A., Frijters, P., 2004. How important is methodology for the estimates of the determinants of happiness? Econ. J. 114 (497), 641-659.

Clark, A.E., 2003. Unemployment as a social norm: psychological evidence from panel data. J. Labor Econ. 21 (2), 323-351.

Clark, A.E., Oswald, A.J., 1996. Satisfaction and comparison income. J. Public Econ. 61 (3), 359-381.

Clark, A.E., Oswald, A.J., 1998. Comparison-concave utility and following behaviour in social and economic settings. J. Public Econ. 70 (1), 133-155.

Falk, A., Ichino, A., 2006. Clean evidence on peer effects. J. Labor Econ. 24 (1), 39 57.

Frijters, P., Leigh, A., 2008. Materialism on the march: from conspicuous leisure to conspicuous consumption? J. Socio-Econ. 37 (5), 1937-1945.

Georges-Kot, S., Goux, D., Maurin, E., 2014. Following the crowd: leisure complementarities beyond the household. IZA Discussion Paper 8714.

Grodner, A., Kniesner, T.J., 2006. Social interactions in labor supply. J. Eur. Econ. Assoc. 4 (6), 1226-1248.

Grodner, A., Kniesner, T.J., 2008. Labor supply with social interactions: econometric estimates and their tax policy implications. Res. Labor Econ. 28, 1-23.

Hamermesh, D.S., 2002. Timing, togetherness and time windfalls. J. Popul. Econ. 15 (4), 601-623.

Hole, A.R., Dickerson, A., Munford, L., 2011. A Review of Estimators for the Fixed-Effects Ordered Logit Model. Technical Report. United Kingdom Stata Users' Group Meetings 2011.

Ichino, A., Maggi, G., 2000. Work environment and individual background: explaining regional shirking differentials in a large italian firm. Q. J. Econ. 115 (3), 1057-1090.

Jenkins, S.P., Osberg, L., 2004. Nobody to play with? The implications of leisure coordination. In: Hamermesh, D.S., Pfann, G.A. (Eds.), The Economics of Time Use (Contributions to Economic Analysis, volume 271). Emerald Group Publishing Limited, pp. 113-145.

Kahneman, D., Krueger, A.B., Schkade, D.A., Schwarz, N., Stone, A.A., 2004. A survey method for characterizing daily life experience: the day reconstruction method. Science 306 (5702), 1776-1780.

Kahneman, D., Thaler, R.H., 2006. Anomalies: utility maximization and experienced utility. J. Econ. Perspect. 20 (1), 221-234.

Van der Klaauw, B., Van Ours, J.C., 2003. From welfare to work: does the neighborhood matter? J. Public Econ. 87 (5), 957-985.

Landers, R.M., Rebitzer, J.B., Taylor, L.J., 1996. Rat race redux: adverse selection in the determination of work hours in law firms. Am. Econ. Rev. 86 (3), 329-348.

Van der Lippe, T., Siegers, J.J., 1994. Division of household and paid labour between partners: effects of relative wage rates and social norms. Kyklos 47 (1), 109-136.

Lykken, D., Tellegen, A., 1996. Happiness is a stochastic phenomenon. Psychol. Sci. 7 (3), 186-189.

Manski, C.F., 1993. Identification of endogenous social effects: the reflection problem. Rev. Econ. Stud. 60 (3), 531-542.

Mas, A., Moretti, E., 2009. Peers at work. Am. Econ. Rev. 99 (1), 112-145.

Maurin, E., Moschion, J., 2009. The social multiplier and labor market participation of mothers. Am. Econ. J. 1 (1), 251-272.

Mujcic, R., Frijters, P., 2015. Conspicuous consumption, conspicuous health, and optimal taxation. J. Econ. Behav. Organ. 111, 59-70.

Nickell, S., 1981. Biases in dynamic models with fixed effects. Econometrica: J. Econ. Soc. 49 (6), 1417-1426.

Oswald, A.J., Powdthavee, N., 2007. Obesity, unhappiness, and the challenge of affluence: theory and evidence. Economic J. 117 (6), 441-454 
Rätzel, S., 2009. Revisiting the Neoclassical Theory of Labour Supply-Disutility of Labour, Working Hours, and Happiness. Technical Report. Otto-von-Guericke University Magdeburg, Faculty of Economics and Management.

Soetevent, A.R., 2006. Empirics of the identification of social interactions; an evaluation of the approaches and their results. J. Econ. Surv. 20 (2), 193-228.

Stiglitz, J.E., 2008. Toward a general theory of consumerism: reflections on Keynes's economic possibilities for our grandchildren. In: Pecchi, L., Piga, G. (Eds.), Revisiting Keynes: Economic Possibilities for Our Grandchildren. MIT Press, pp. 41-86.

Stutzer, A., Lalive, R., 2004. The role of social work norms in job searching and subjective well-being. J. Eur. Econ. Assoc. 2 (4), 696-719.

Topa, G., 2001. Social interactions, local spillovers and unemployment. Rev. Econ. Stud. 68 (2), 261-295.
Veblen, T., 1899. The Theory of the Leisure Class: An Economic Study in the Evolution of Institutions. Macmillan \& Company, Limited.

Vendrik, M., 1998. Unstable bandwagon and habit effects on labor supply. J. Econ. Behav. Organ. 36 (2), 235-255.

Vendrik, M., 2003. Dynamics of a household norm in female labour supply. J. Econ. Dyn. Control 27 (5), 823-841.

Weinberg, B.A., Reagan, P.B., Yankow, J.J., 2004. Do neighborhoods affect hours worked? Evidence from longitudinal data. J. Labor Econ. 22 (4), 891-924.

Woittiez, I., Kapteyn, A., 1998. Social interactions and habit formation in a model of female labour supply. J. Public Econ. 70 (2), 185-205.

Wooldridge, J.M., 1995. Selection corrections for panel data models under conditional mean independence assumptions. J. Econ. 68 (1995), 115-132. 